\title{
Variability in the metabolism of saccharides in bladder and colon cancer cell lines
}

\author{
Michael A. Lea ${ }^{1, *}$, and Charles desBordes ${ }^{1,2}$ \\ 1'Department of Microbiology, Biochemistry and Molecular Genetics, Rutgers New Jersey Medical School, Newark, NJ, USA \\ ${ }^{2}$ Department of Biology, Medgar Evers College - City University of New York, Brooklyn, NY, USA
}

\begin{abstract}
The addiction of most cancer cells to the metabolism of glucose is well established. The metabolism by cancer cells of other saccharides is less well characterized. We have studied the impact of mono- and disaccharides on growth of human bladder and colon cancer cells. Substitution for glucose by other monosaccharides (fructose, galactose and mannose) resulted in similar growth in some cell lines, but growth was greatly diminished in others. HT29 colon cancer cells were the only cell line to have a substantial increased growth with trehalose. In those cell lines in which alkaline phosphatase activity could be induced after incubation with butyrate, induction was observed with any of the saccharides that were examined. For the Caco-2 and HT29 colon cancer cells, co-incubation with 2-deoxyglucose was more inhibitory for growth with fructose than with glucose as substrate. There was a similar situation with some bladder cancer cell lines (5637, HT1197 and RT4) whereas with other bladder cancer cells (HT1376, T24 and UM-UC-3) 2-deoxyglucose caused greater inhibition with glucose. It was apparent that maltose could enhance growth to an extent that was similar to that seen with glucose and was not seen with other disaccharides. The enhanced growth with maltose required maltase activity in serum added to growth medium. In conclusion, the stimulation of growth by saccharides exhibits considerable variability with different molecules.
\end{abstract}

Keywords: Warburg effect; bladder cancer; colon cancer; monosaccharides; disaccharides; growth

\section{Introduction}

The tendency of cancer cells to have high rates of glycolysis even under aerobic conditions has become known as the Warburg effect [1, 2]. The high uptake and metabolism of glucose in most cancer cells is well established [3]. The use of other saccharides is less well characterized. In this study we have compared the impact of glucose on growth of bladder and colon cancer cells with the effects of other monosaccharides and with disaccharides. It is hoped that this information can serve as a guide in nutritional intervention and as an indicator for points of regulatory control. Two potential regulatory molecules, butyrate and 2-deoxyglucose, have been investigated. Butyrate is a short chain fatty acid that serves as an important nutrient for normal colonocytes but is also a histone deacetylase inhibitor that could influence gene expression. Butyrate has been observed to inhibit growth of bladder and colon cancer cells [4]. 2-deoxyglucose is of interest in monitoring glucose uptake by cancer cells and in addition it can serve as an inhibitor of glycolysis and tumor growth [5]. An objective in cancer research has been to identify unifying trends in cancer metabolism that can serve as a general guide to preventive or therapeutic intervention. Increasingly, however, there is evidence for great diversity in the molecular changes that can occur even within a particular tissue type [6]. Results in the present study may add to that conclusion.

\section{Materials and Methods \\ Reagents}

Monosaccharides and disaccharides were obtained from Sigma-Aldrich (St. Louis, MO, USA).

\section{Cells and determination of growth}

Human bladder cancer cell lines, namely 5637, HT1197, HT1376, RT4, T24 and UM-UC-3, and human colon cancer

*Corresponding author:Michael A. Lea, Department of Microbiology, Biochemistry and Molecular Genetics, Rutgers New Jersey Medical School, 225 Warren Street, Newark, New Jersey, 07103, USA. Tel.: +1 9739725345; Fax: +1 9739721286; Email: lea@njms.rutgers.edu

Received 7 June 2020 Revised 22 July 2020 Accepted 29 July 2020 Published 3 August 2020

Citation: Lea MA, desBordes C. Variability in the metabolism of saccharides in bladder and colon cancer cell lines. J Cancer Res Ther. 2020; 8(4):21-27. DOI: 10.14312/2052-4994.2020-4

Copyright: ( 2020 Lea MA, et al. Published by NobleResearch Publishers. This is an open-access article distributed under the terms of the Creative Commons Attribution License, which permits unrestricted use, distribution and reproduction in any medium, provided the original author and source are credited. 
cells Caco-2 and HT29 were obtained from the American Type Culture Collection (Rockville, MD, USA), and were incubated at $37^{\circ} \mathrm{C}$ with $5 \%$ carbon dioxide. After plating 5000 cells in 96 well plates in 0.2 ml RPMI-1640 with 5\% fetal calf serum for 24 hours, medium was replaced with either control medium or medium containing saccharides. Monosaccharides and disaccharides were added at a concentration of $2 \mathrm{mg}$ per $\mathrm{ml}$ corresponding to the concentration of glucose in RPMI-1640 medium. After a further 72-hour incubation cell growth was determined by the increase in protein using staining with sulforhodamine $B$ essentially as described by Vichai and Kirtikara [7]. The medium was aspirated and the cells were incubated with $0.1 \mathrm{ml} \mathrm{10 \%} \mathrm{trichloracetic} \mathrm{acid} \mathrm{on} \mathrm{ice} \mathrm{for} 60$ minutes. After removing the $10 \%$ trichloroacetic acid, the fixed cells were washed twice with $0.3 \mathrm{ml}$ water and incubated with $0.1 \mathrm{ml}$ $0.057 \%$ sulforhodamine $B$ in $1 \%$ acetic acid for 30 minutes. Unbound dye was removed with two washes with $0.3 \mathrm{ml}$ $1 \%$ acetic acid and the bound dye was eluted with $0.2 \mathrm{ml}$ $10 \mathrm{mM}$ Tris solution ( $\mathrm{pH} 10.5)$. Absorbance of the bound dye was measured at $510 \mathrm{~nm}$.

\section{Alkaline phosphatase activity}

Assays were performed directly on cells incubated in 96 well plates due to the localization of the enzyme on the plasma membrane. Medium was removed and the cells were incubated for $30 \mathrm{~min}$ at $37^{\circ} \mathrm{C}$ with $100 \mu \mathrm{l}$ solution containing the substrate and buffer. Reagents were obtained from Sigma-Aldrich (St. Louis, MO, USA). The substrate and buffer were $5 \mathrm{mM}$ para-nitrophenyl phosphate and 0.75 M 2-amino-2-methyl-1-propanol, pH 10.3. The incubation was stopped by the addition of 100 $\mu l 0.5 \mathrm{~N} \mathrm{NaOH}$. The formation of product was monitored by the absorption of light at $410 \mathrm{~nm}$. Enzyme activities per unit protein were calculated by dividing the absorbance for the colorimetric enzyme assay by the light absorbance determined by staining with sulforhodamine B. A unit protein corresponded to that giving an absorbance of 1.0 at $510 \mathrm{~nm}$.

\section{Glucose assay}

Glucose was assayed with $2 \mu$ cell culture medium using glucose oxidase and peroxidase reagent from SigmaAldrich. This is a colorimetric procedure in which the oxidation of glucose is coupled with glucose oxidase and peroxidase to the oxidation of dianisidine. Incubation at room temperature was performed for 30 minutes in a total volume of $0.3 \mathrm{ml}$, including $80 \mu \mathrm{l} 1 \mathrm{M}$ sodium phosphate $(\mathrm{pH}$ 6.0). The incubation was stopped by the addition of $0.2 \mathrm{ml} 12 \mathrm{~N}$ sulfuric acid. Light absorbance at $540 \mathrm{~nm}$ was measured with $0.2 \mathrm{ml}$ of the mixture using a BioTek Epoch plate reader.

\section{Statistical evaluation}

Data are presented as mean \pm standard deviation for three or a greater number of determinations. Statistical significance of the results was determined by analysis of variance followed by Dunnett's test for multiple comparisons or by a two-tailed Student's t-test for comparison between two groups. A p-value less than 0.05 was considered statistically significant. Statistical analysis was performed using the InStat program from Graphpad Software, Inc.

\section{Results}

The data in Figure 1 indicate that for four bladder cancer cell lines and two colon cancer cell lines growth in RPMI1640 medium with $5 \%$ fetal calf serum growth with an initial concentration of $2 \mathrm{mg}$ glucose per $\mathrm{ml}$ was significantly greater than in the absence of added saccharide. Substitution for glucose by other monosaccharides (fructose, galactose and mannose) resulted in similar growth in some cell lines but growth was greatly diminished in others. Growth with galactose tended to be less than with the other monosaccharides. The tendency was for growth not to be increased by the addition of disaccharides except for maltose which caused significantly increased growth in most cases. HT29 colon cancer cells were the only cell line to have a substantial increased growth with trehalose.

The results in Figure 2a confirm that with HT29 colon cancer cells growth is greatly increased by both mannose and glucose but there is only a small increase with $2 \mathrm{mM}$ butyrate as an energy source. In contrast, the addition of butyrate decreased the growth seen with mannose or butyrate as single agents. On the other hand the induction of alkaline phosphatase by butyrate was also seen when butyrate was co-incubated with either mannose or glucose (Figure 2b). The data in Figure 3 indicate that induction of alkaline phosphatase activity by butyrate was also seen when butyrate was co-incubated with fructose or galactose in four cell lines where induction of alkaline phosphatase by butyrate has been previously observed [4].

The stimulation of growth by maltose raised the question of whether a similar response might be seen with isomaltose. This was addressed in the experiments recorded in Figure 4 that also considered whether growth stimulation by maltose will be affected by 2-deoxyglucose, an inhibitor of glycolysis. The data indicate that for the HT1197 and T24 bladder cancer cell lines the marked growth stimulation by glucose and maltose is inhibited by $5 \mathrm{mM}$ 2-deoxyglucose and is not seen with isomaltose. Studies on the effects of 2-deoxyglucose on growth in the presence of monosaccharides are summarized in Table 1. For the Caco-2 and HT29 colon cancer cells, co-incubation with 2-deoxyglucose was more inhibitory for growth with fructose than with glucose as substrate. There was a similar situation with some bladder cancer cell lines (5637, HT1197 and RT4) whereas with other bladder cancer cells (HT1376, T24 and UM-UC-3) 2-deoxyglucose caused greater inhibition with glucose than with fructose.

Influenced by observations in the literature that serum from some mammalian species may exhibit maltase activity [8, 9] we compared changes in glucose levels in the medium of cells incubated for 72-hours in the presence or absence of $5 \%$ fetal calf serum. The data in Figure 5 for HT1376 bladder cancer cells and HT29 colon cancer cells indicate that the presence of fetal calf serum increases the level of glucose with maltose in the medium but not with glucose in the medium. Evidence for action of maltase in serum in the absence of cells is provided by the data in Figure 6 . Incubation of medium with fetal calf serum for 72-hours did not significantly affect the glucose concentration with glucose in the medium but the presence of serum caused a large significant increase of glucose with maltose in the medium. 

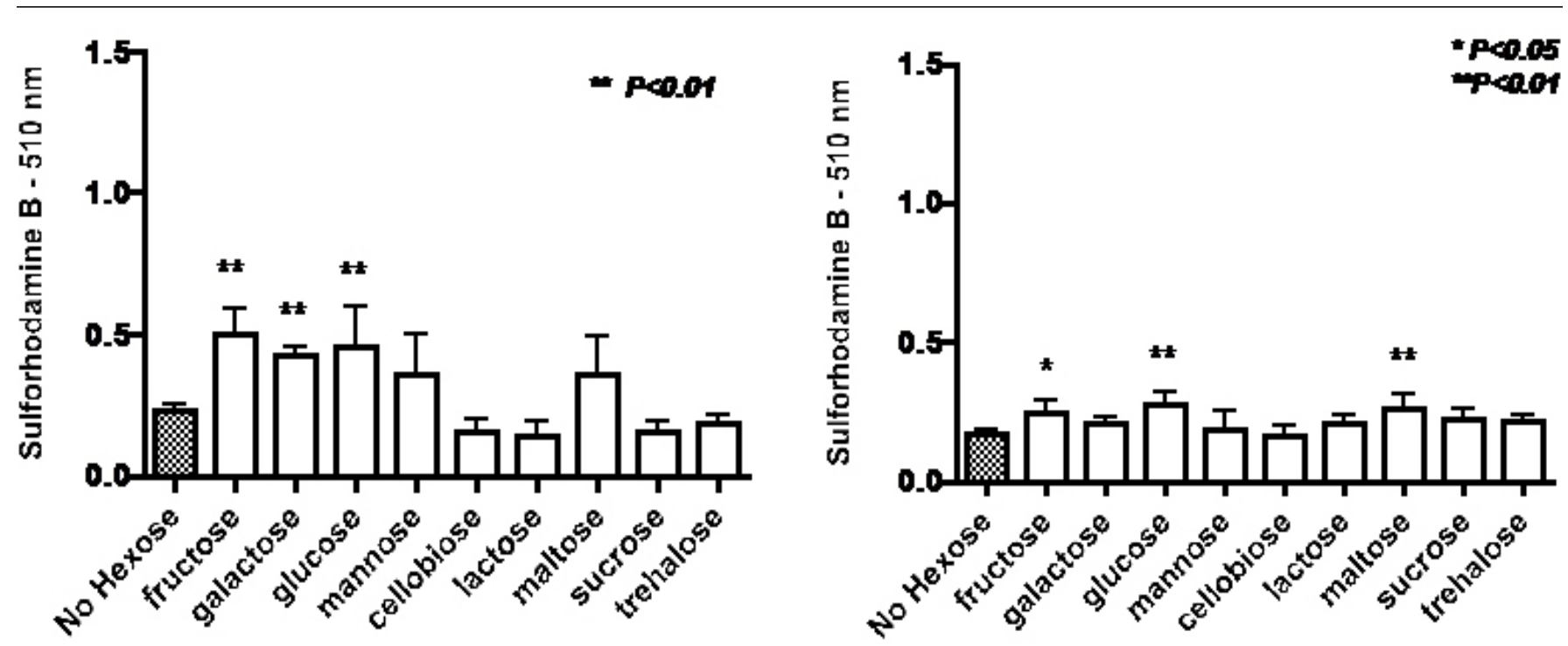

(a) Bladder 5637

(b) Colon Caco-2
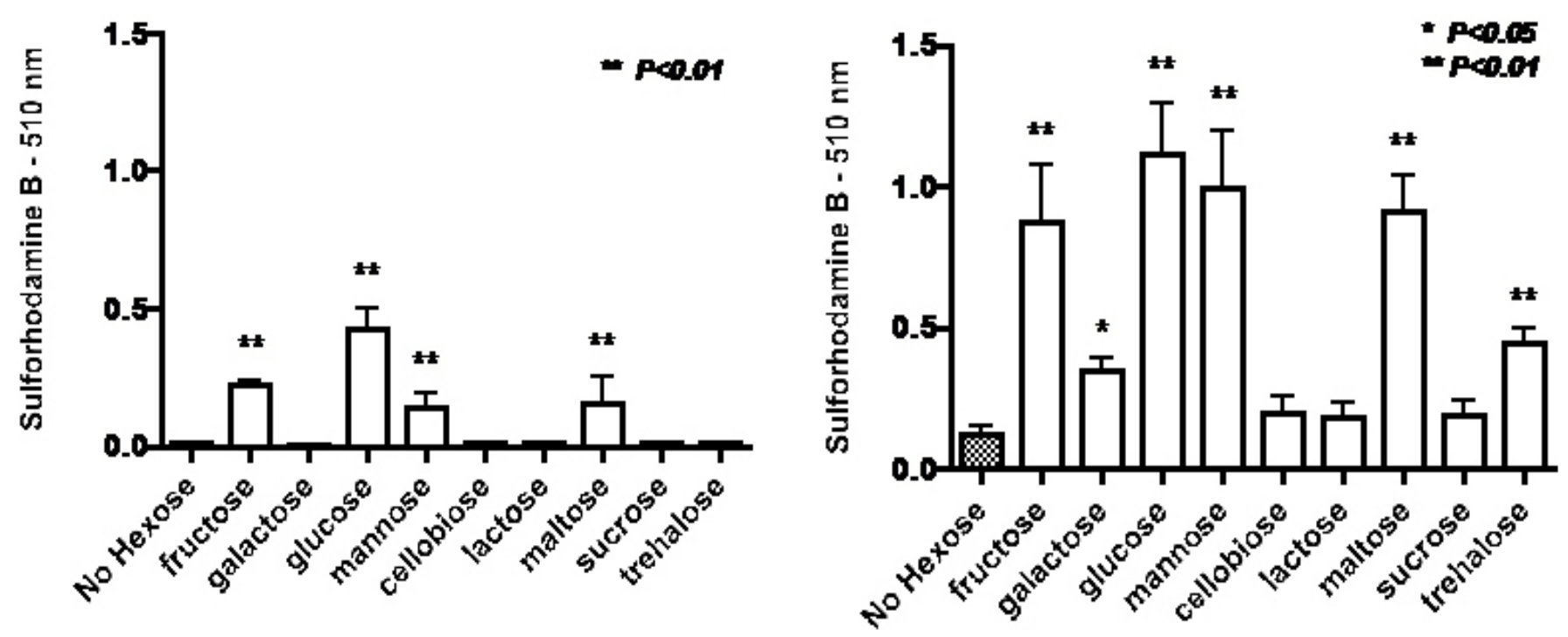

(c) Bladder HT1376

(d) Colon HT29
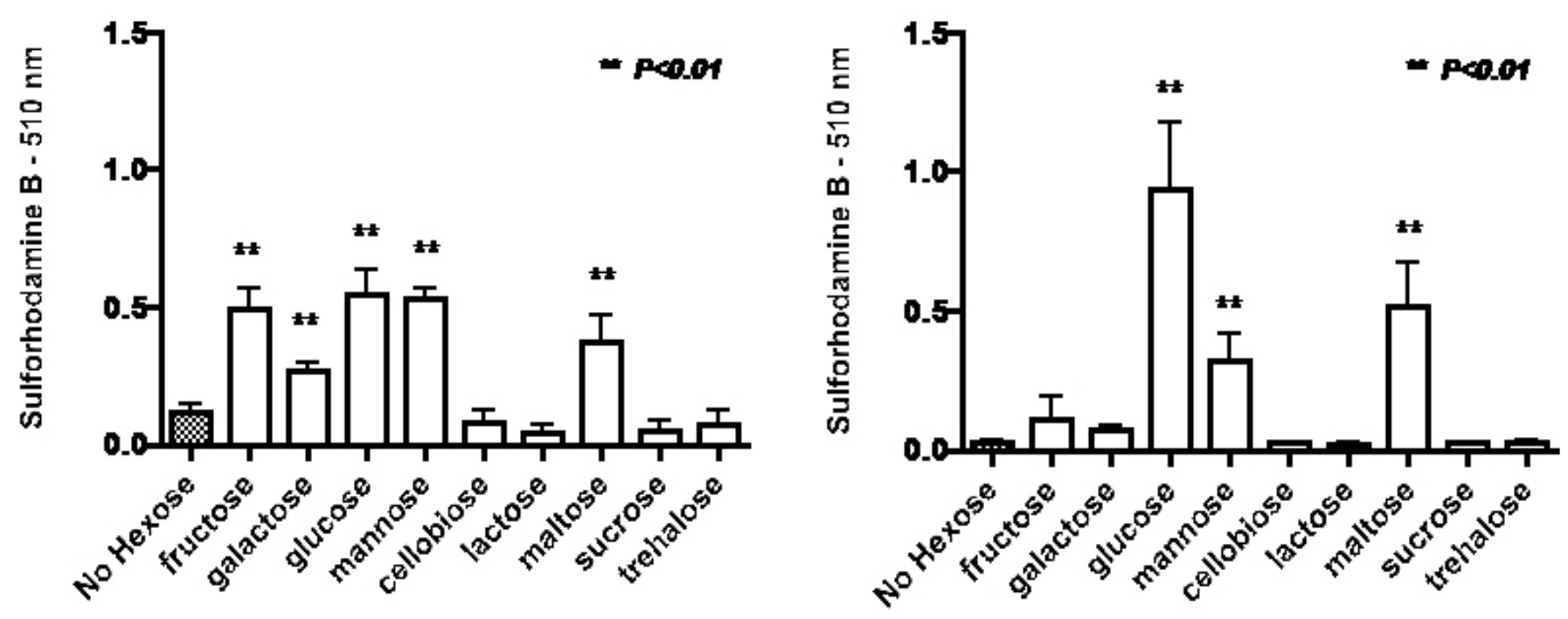

Figure 1 Effects of monosaccharides and disaccharides $(2 \mathrm{mg} / \mathrm{ml})$ on the growth of cell lines as determined by sulforhodamine B assay after a 72 -hour incubation. Data are the means \pm SD of 6 determinations. Significantly different from control at $* p<0.05$ and $* * p<0.01$. 


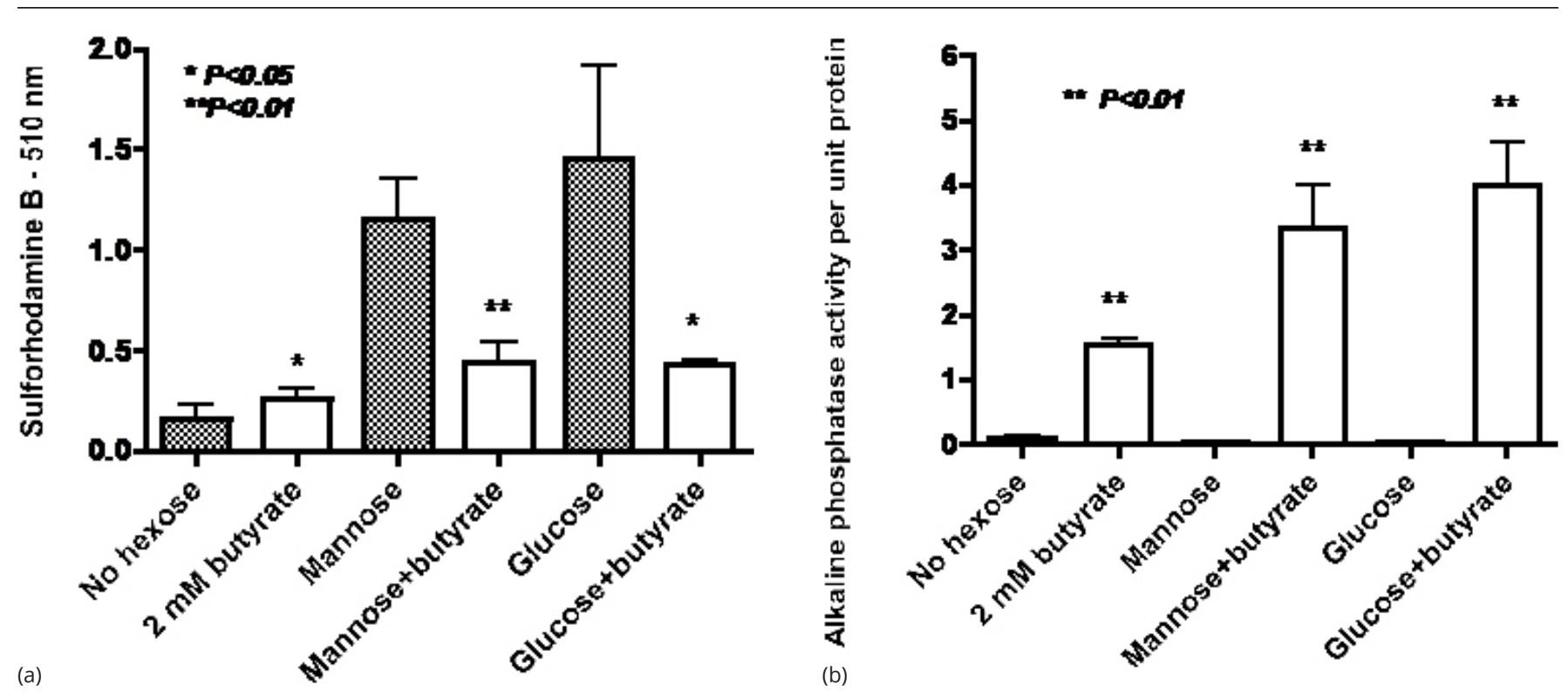

Figure 2 Effects of butyrate $(2 \mathrm{mM})$, mannose and glucose $(2 \mathrm{mg} / \mathrm{ml})$ on growth and alkaline phosphatase activity in HT29 colon cancer cells after a 72 hour incubation: (a) growth as determined by sulforhodamine B assay, (b) alkaline phosphatase activity per unit protein. Data are the means \pm SD of 6 determinations. Significantly different from control at * $p<0.05$ and $* * p<0.01$.
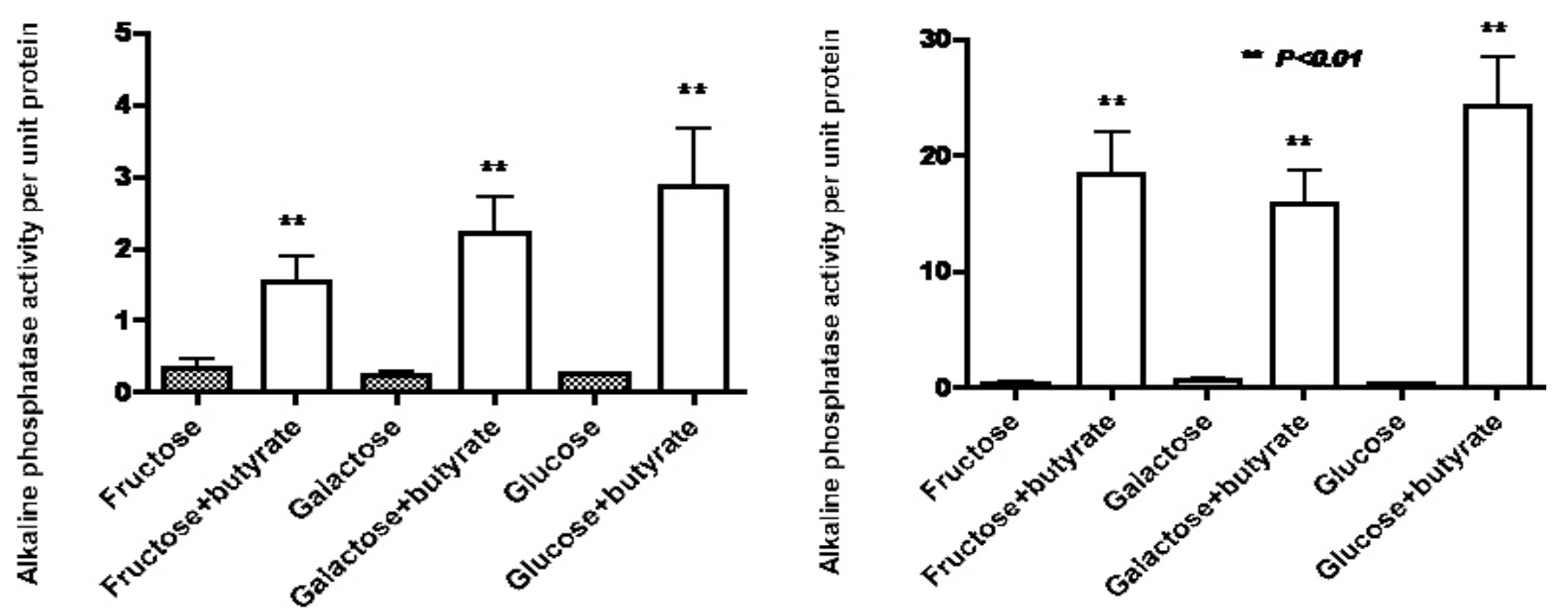

(a) Bladder 5637

(b) Colon Caco-2
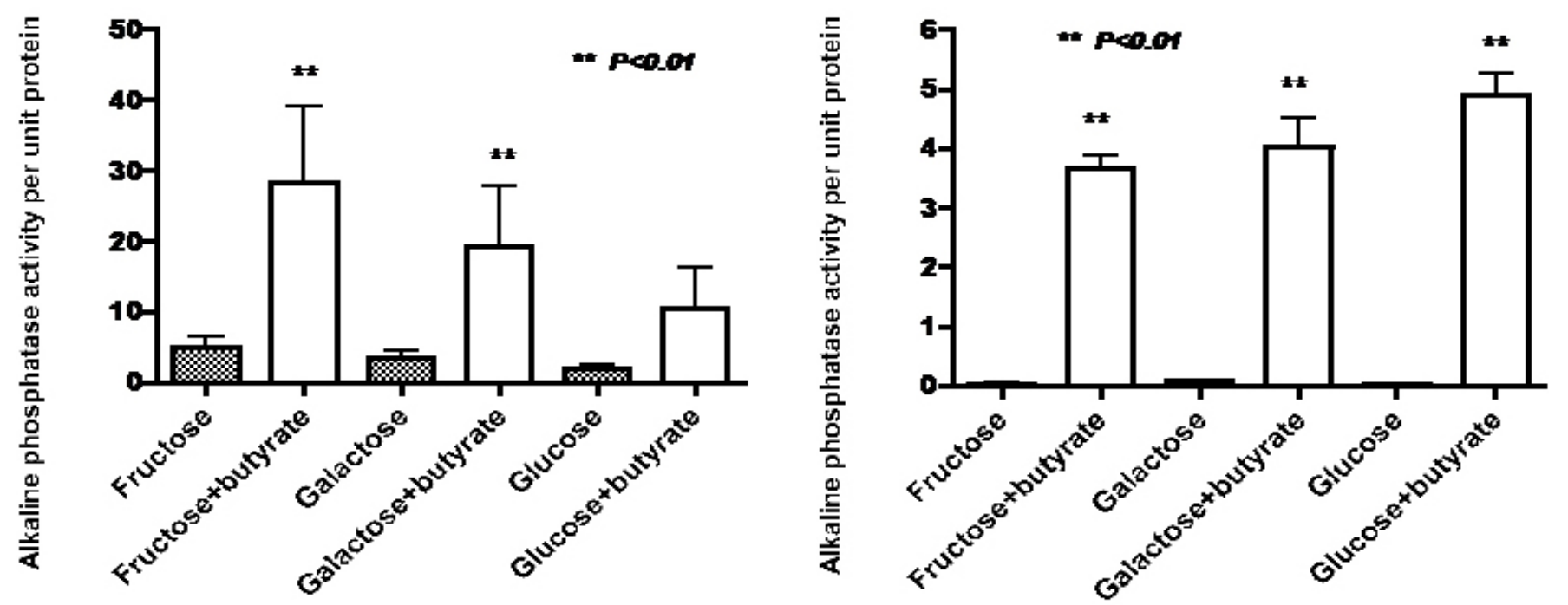

(c) Bladder HT1197

(d) Colon HT29

Figure 3 Effects of butyrate $(2 \mathrm{mM})$, mannose and glucose $(2 \mathrm{mg} / \mathrm{ml})$ on alkaline phosphatase activity per unit protein in cells after a 72 -hour incubation. Data are the means \pm SD of 6 determinations. Significantly different from control at $* p<0.05$ and ${ }^{*} \mathrm{p}<0.01$. 

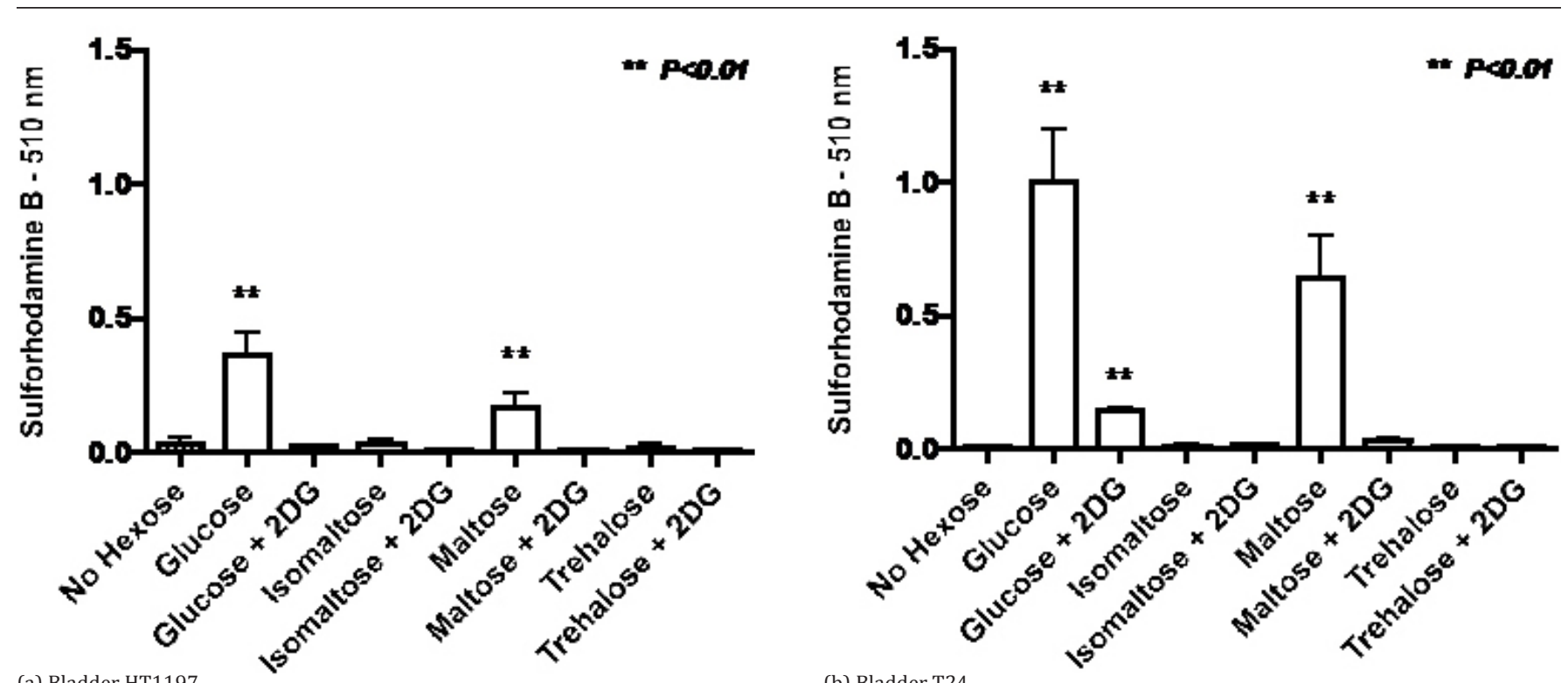

(a) Bladder HT1197

(b) Bladder T24

Figure 4 Effects of 2-deoxyglucose $(5 \mathrm{mM})$, glucose, isomaltose and mannose $(2 \mathrm{mg} / \mathrm{ml})$ on the growth of cell lines as determined by sulforhodamine B assay after a 72 -hour incubation of bladder cancer. Data are the means \pm SD of 6 determinations. Significantly different from control at $* p<0.05$ and $* * p<0.01$.

Table 1 Percent inhibition of growth by 2-deoxyglucose (2DG) in bladder and colon cancer cell lines grown on glucose, fructose or mannose.

\begin{tabular}{|c|c|c|c|c|c|c|}
\hline \multirow{2}{*}{ Cell lines } & \multicolumn{2}{|l|}{ Fructose+ } & \multicolumn{2}{|l|}{ Glucose+ } & \multicolumn{2}{|l|}{ Mannose+ } \\
\hline & $1 m M 2 D G$ & $5 m M 2 D G$ & $1 \mathrm{mM} 2 \mathrm{DG}$ & $5 m M 2 D G$ & $1 \mathrm{mM} 2 \mathrm{DG}$ & $5 m M 2 D G$ \\
\hline Colon Caco-2 & 52 & 81 & 11 & 28 & 4 & 19 \\
\hline HT29 Bladder & 67 & 90 & 39 & 80 & 43 & 69 \\
\hline 5637 & 52 & 76 & 0 & 41 & 25 & 34 \\
\hline HT1197 & 34 & 63 & 9 & 24 & 23 & 41 \\
\hline HT1376 & 16 & 34 & 48 & 72 & 21 & 15 \\
\hline RT4 & 74 & 85 & 18 & 68 & 34 & 55 \\
\hline T24 & 7 & 47 & 61 & 84 & 13 & 16 \\
\hline UM-UC-3 & 0 & 58 & 77 & 91 & 19 & 46 \\
\hline
\end{tabular}

Cell lines were incubated for 72 hours in medium containing monosaccharides at a concentration of 2 mg per ml.

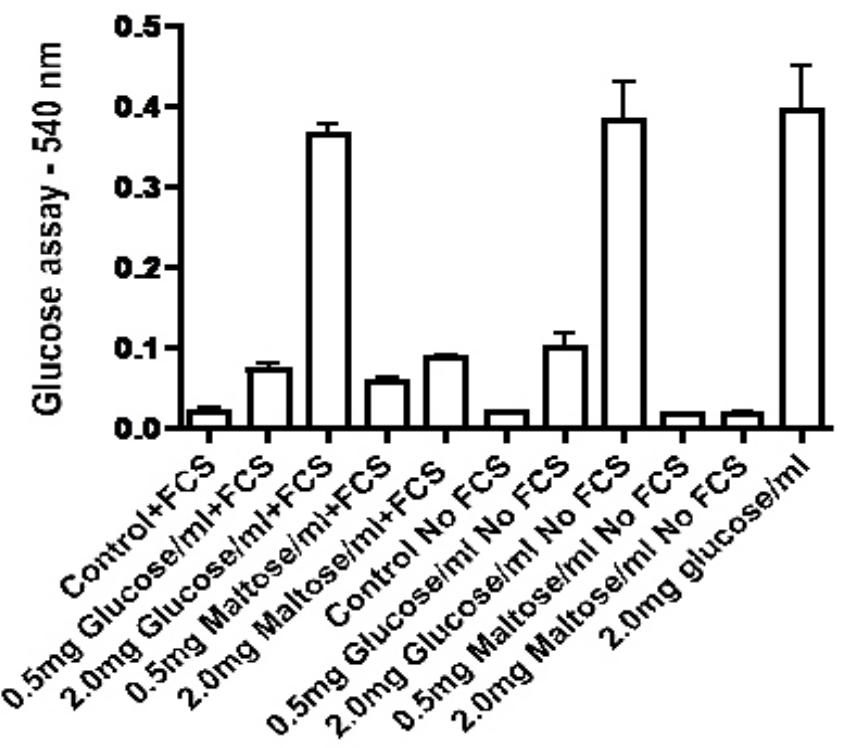

(a) Bladder HT1376
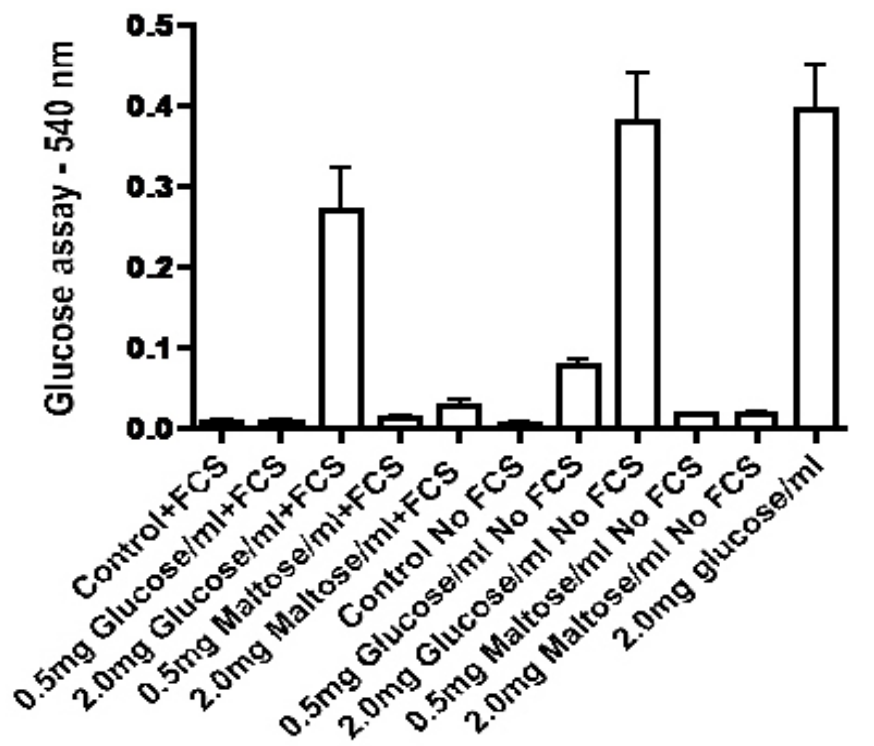

(b) Colon HT29

Figure 5 Effects on glucose levels in the medium of HT1376 bladder cancer cells (a) and HT29 colon cancer cells (b) incubated with glucose or maltose at an initial concentration of $2 \mathrm{mg}$ per $\mathrm{ml}$ after a 72 -hour incubation in the presence or absence of $5 \%$ fetal calf serum. Data are the means \pm SD of 6 determinations and can be compared with the right-hand bar for the absorbance given by assay of an equal volume of a solution containing 2 mg glucose per ml. 


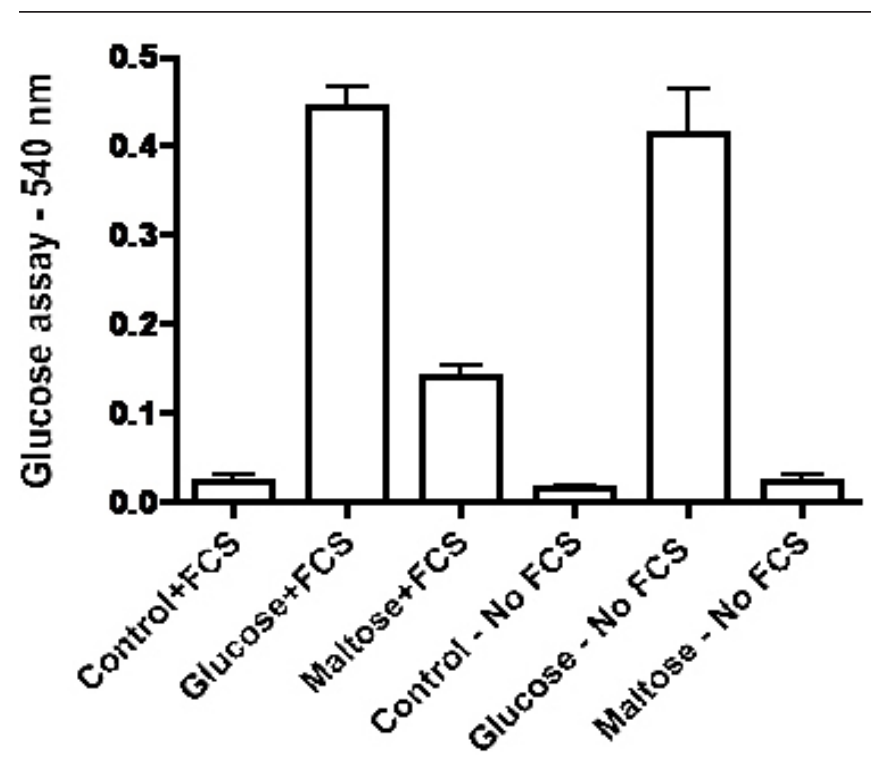

Figure 6 Effect of $5 \%$ fetal calf serum (FCS) on glucose assays after a 72hour incubation at $37^{\circ} \mathrm{C}$ of medium containing $2 \mathrm{mg}$ per $\mathrm{ml}$ of glucose or maltose in the absence of cancer cells. Data are the means \pm SD of 6 determinations.

\section{Discussion}

The relative contribution of glucose and fructose as energy sources is a variable in the contemporary diet. Major sources of fructose are sucrose and high fructose corn syrup. Goncalves et al. reported that high fructose corn syrup enhances intestinal tumor growth in mice [10]. In the present work fructose stimulated growth of some cell lines in a similar manner to growth with glucose. However, with UM-UC-3 bladder cancer cells growth was much greater with glucose than with fructose. Mannose has been reported to impair tumor growth and enhance chemotherapy [11]. In contrast, in the present work there was increased growth when mannose was present in the medium. With the bladder and colon cancer cells that were studied, galactose tended to be less effective than glucose, fructose and mannose in stimulating growth.

Growth can be inhibited by butyrate in bladder and colon cancer cells. In some but not all cell lines, inhibition of growth is accompanied by induction of alkaline phosphatase activity that has been considered a marker of cell differentiation. We noted in cell lines where alkaline phosphatase activity can be induced by butyrate, that induction can occur in the presence of any of the monosaccharides that were examined. 2-deoxyglucose is another molecule that can inhibit glycolysis and proliferation. The degree of growth inhibition was found to be quite variable between the different cell lines that were examined and for some cell lines was greater with fructose than with glucose while with the T24 and UM-UC-3 bladder cancer cells there was notably greater inhibition with glucose than with fructose. Glucose and mannose are epimers that differ in the orientation of the oxygen atom at carbon 2. This means that 2-deoxyglucose could equally well be called 2-deoxymannose and it has been found in some systems that mannose can give a degree of protection against effects of 2-deoxyglucose.

In the present work growth inhibition by 2-deoxyglucose tended to be greater with glucose than with mannose as the energy source but some exceptions were noted. Woodward and Hudson [12] observed that fructose metabolism in liver was relatively insensitive to inhibition by 2-deoxyglucose, whereas in two cancer cell lines 2-deoxyglucose caused greater inhibition of fructose metabolism than metabolism of glucose. In view of the high activity of fructokinase (ketohexokinase) in liver it appears possible that fructokinase activity and hexokinase activity may respond differently to the action of 2-deoxyglucose. Further characterization of the action of 2-deoxyglucose on fructose metabolism in bladder and cancer cells may require not only studies on fructokinase and hexokinases but also the combination of techniques including metabolomics that have been reviewed by $\mathrm{Lu}$ and Zhan [13].

There have been few reports of transporters for disaccharides in animal cells. It is generally anticipated that hydrolysis to constituent monosaccharides will be necessary before uptake into cells. We did not see stimulation of growth when the saccharide in the medium was cellobiose, isomaltose, lactose or sucrose suggesting that the cells lacked a capacity to hydrolyze those disaccharides. In the case of trehalose, HT29 colon cancer cells were an exception in that growth was stimulated by trehalose. Trehalose is not thought to be a major nutrient for mammalian cells but it has been reported to have a variety of effects including actions on subcellular trafficking and increasing energy metabolism and autophagy [14,15]. The action on HT29 colon cancer cells may merit further investigation. Maltose was the only disaccharide that we found caused a consistent increase in cell growth. A study on intravenously injected maltose indicated metabolism in humans can occur without hydrolysis in the gastrointestinal tract [16]. The presence of maltase activity in serum of some species has been observed and utilization of maltose by cells in culture has been attributed to serum maltase [17].

On the other hand, Leong and coworkers have presented evidence for an adaptive response in which maltose can serve as an energy source in protein-free mammalian cell cultures $[18,19]$. Our studies with cells incubated with and without serum and on incubations of maltose with serumcontaining medium suggest that maltase-containing fetal calf serum was necessary for stimulation of growth by maltose in bladder and colon cancer cells. In future studies it will be interesting to investigate if newborn or adult bovine serum or human serum can support growth stimulation by maltose in human cancer cells.

\section{Conclusion}

Studies with human bladder and colon cancer cell lines have indicated considerable variability in the degree to which different monosaccharides can support growth. Inhibition by 2-deoxyglucose of growth stimulation by monosaccharides can vary with different cell lines and monosaccharide energy source. Growth stimulation was not seen with several disaccharides and the growth stimulation observed with maltose appears to be dependent on maltase activity present in fetal calf serum. 


\section{Acknowledgements}

This work was supported in part by the Alma Toorock Memorial for Cancer Research. We are grateful to Sarah Ayoubi and Annika Nungra for technical assistance in a portion of this work.

\section{Conflict of interest}

Authors declare no conflict of interest.

\section{References}

[1] Koppenol WH, Bounds PL, Dang CV. Otto Warburg's contributions to current concepts of cancer metabolism. Nature Rev Cancer. 2011; 11(5):325-337.

[2] Otto AM. Warburg effect(s)-a biographical sketch of Otto Warburg and his impacts on tumor metabolism. Cancer Metab. 2016; 4:5.

[3] Hirschey MD, DeBerardinis RJ, Diehl AME, Drew JE, Frezza C, et al. Dysregulated metabolism contributes to oncogenesis. Seminars Cancer Biol. 2015; 35:S129-S150.

[4] Lea MA, Batista E, Cue L, desBordes C. Variability in the induction of alkaline phosphatase by histone deacetylase inhibitors in bladder and colon cancer cell lines. J Cancer Res Ther. 2019; 7(2):9-16.

[5] Lea MA, Chacko J, Bolikal S, Hong JY, Chung R, et al. Addition of 2-deoxyglucose enhances growth inhibition but reverses acidification in colon cancer cells treated with phenformin. Anticancer Res. 2011; 31(2):421-426.

[6] Faubert B, Solmonson A, DeBerardinis RJ. Metabolic reprogramming and cancer progression. Science. 2020; 368(6487):eaaw5473.

[7] Vichai V, Kirtikara K. Sulforhodamine B colorimetric assay for cytotoxicity screening. Nature Protoc. 2006; 1(3):1112-1116.

[8] Lieberman I, Eto WH. Purification and properties of equine serum maltase. J Biol Chem. 1957; 225(2):899-908.

[9] Van Handel E. Trehalase and maltase in the serum of vertebrates. Comp Biochem Physiol. 1968; 26(2):561-566.

[10] Goncalves MD, Lu C, Tutnauer J, HartmanTE, Hwang SK, et al. Highfructose corn syrup enhances intestinal tumor growth in mice. Science. 2019; 363(6433):1345-1349.

[11] Gonzalez PS, O'Prey J, Cardaci S, Barthet VA, Sakamakill, et al. Mannose impairs tumour growth and enhances chemotherapy. Nature. 2018; 563(7733):719.

[12] Woodward GE, Hudson MT. The effect of 2-desoxy-D-glucose on glycolysis and respiration of tumor and normal tissues. Cancer Res. 1954; 14:599-605.

[13] Lu M, Zhan X. The crucial role of multiomic approach in cancer research and clinically relevant outcomes. EPMA J. 2018; 9(1):77-102.

[14] Tien NT, Karaca I, Tamboli IY, Walter J. Trehalose alters subcellular trafficking and metabolism of the Alzheimer-associated amyloid precursor protein. J Biol Chem. 2016; 291(20):10528-10540.

[15] Arai C, Arai N, Arai S, Yoshizane C, Miyata S, et al. Continuous intake of trehalose induces white adipose tissue browning and enhances energy metabolism. Nutr Metab. 2019; 16:45.

[16] Young JM, Weser E. The metabolism of circulating maltose in man. J Clin Invest. 1971; 50(5):986-991.

[17] Scannell J, Morgan MJ. The regulation of carbohydrate metabolism in animal cells: isolation of starch- and maltose-utilizing variants. Biosci Rep. 1982; 2(2):99-106.

[18] Leong DSZ, Tan JGL, Chin CL, Mak SY, Ho YS, et al. Evaluation and use of disaccharides as energy source in protein-free mammalian cell cultures. Sci Rep. 2017; 7:45216.

[19] Leong DSZ, Teo BKH, Tan JGL, Zhang P, Ng SK. Application of maltose as energy source in protein-free $\mathrm{CHO}-\mathrm{K} 1$ culture to improve the production of recombinant monoclonal antibody. Sci Rep 2018; 8(1):4037. 